\title{
Does Awareness Influence Choice of Waste Disposal Methods? A Case of Migori Town, Kenya
}

\author{
Michael Ndwiga $^{1} \quad$ Lilian Nyambura $^{2 *} \quad$ MaryBennah Kuloba $^{3} \quad$ Leonard Ngaithe $^{4}$ \\ 1.The University of Nairobi, School of Economics, P. O. Box 30197 - 00100, GPO, Nairobi Room GW 210, \\ Kenya \\ 2.Utafiti International Limited - Technology Research Company, P.O BOX 13506-00800, Para mount Plaza \\ Nairobi, Kenya \\ 3.Ministry of Trade, Kenya, P.O BOX 30418-00100, Social Security House, Block A Nairobi, Kenya
}

\begin{abstract}
Rapid economic growth, urbanization and population increase have fueled the production of large amounts of waste to the environment. Even so, the management of such waste has become a huge problem in many towns in developing nations. This has also led to the emergence of different methods of dumping waste such as; dumping in the dustbins, by the roadside, burying and even burning. This paper sought to give insights and inform policy on waste disposal methods and the level of awareness on proper garbage disposal practices. The research was carried out in Migori County in Kenya. Purposive sampling was used to select the county while random sampling was used to select the respondents. Probit regression model was utilized. The findings indicate that awareness of proper waste disposal, education, age, gender and household size were the key determinants of the method one settles for while disposing waste. The most used waste disposal method was disposing off in the dustbins which was influenced by respondents being more aware and sensitized about the importance of proper waste disposal methods. The paper concludes that more information on proper waste disposal methods should be aired on radio and TV. Since public awareness and attitude has an impact on all stages of the waste management process, the government as well as NGOs should make efforts to increase public awareness on waste disposal methods and participation regarding waste management challenges in developing countries.
\end{abstract}

Keywords: Knowledge of waste disposal methods, Choice of disposal methods, Multivariate Probit model

DOI: $10.7176 /$ CER/11-7-04

Publication date: August $31^{\text {st }} 2019$

\section{Introduction}

Waste generation around the world and disposal rates are rising (World Bank, 2018). According to Tadesse, Ruijs \& Hagos (2008), many cities of developing and low-income countries suffer from severe poor waste management, large amount of refuse is poorly disposed, often in dumps that are unregulated and also burned in open fields, endangering the environment as well as health. Further, annual generation of waste is expected to rise by $70 \%$ from 2016 levels to 3.40 billion tones in 2050 as a result of urbanization as well as population growth (World Bank, 2018). In conclusion, globally, management of solid waste and awareness is a serious disaster. The continuously increasing share of the population residing in urban centers poses serious challenges to the provision of solid waste management services by the municipalities that are short of funds, deficient in organization, have poor equipment for waste collection, and lack urban planning (Rotich et al., 2006; Parrot et al.,2009).

Africa, according to Guneralp (2017) is known to be the least developed region in the world with $38 \%$ urbanization and even though this is low compared to many other countries in the world, African countries are experiencing rapid development with growth rate of four percent per annum, which implies that the countries in Africa are now faced with huge amount of municipal garbage which has direct effect on the peoples wellbeing and safety (Larissa et al, 2019). Hence, one of the major problems in urban centers nowadays is the collection, treatment, transportation, storage, and eventual disposal of waste James (2012). Consequently, people have witnessed a relatively poor waste management practices characterized by indiscriminate dumping of refuse in water bodies and isolated places which further exacerbates the already low sanitation level in most African countries (Bello, Ismail, Kabbashi,2016).

Across all major towns in Kenya study reveals a common waste management problem (Oyake, 2018). Mounds of uncollected garbage are the order of the day, leaving residents in urban centers at risk of disease outbreaks and attempts by various county governments and the environment ministry to clear the mess has been curtailed especially due to rising human population and slums sprouting faster than authorities can manage their trash (Sibanda et al, 2017). Implying, as the population balloons so does garbage. Nairobi, the capital city alone generates an estimated 3,000 tons of garbage everyday according to The African Population and Health Research Center (APHRC). However, according to George (2019) only half of it is collected and as it is, ineffectiveness by county governments to collect and dispose waste has resulted to private garbage collectors and youth groups who collect rubbish at a fee. Unfortunately, not all waste gets to the dump sites or recyclers; some end up on city streets and along roads in major urban centers and estates. The situation is made worse by those who cannot afford the 
fee because they dump waste anywhere (Mutanu,2018). This background informed the researchers to examine awareness and choice of waste disposal methods among residents of Migori County, Western of Kenya. The research sought to give insights on respondent's knowledge of proper waste disposal methods, and what influences choice of the method of disposing refuse one adopts.

\section{Objectives}

i) To estimate factors influencing waste disposal methods in Migori town.

\section{Literature Review}

Waste management should be a continuous and dynamic process giving insight to the developing technology in coming up with new means to effectively handle waste disposal. Improper refuse disposal and collection is a significant concern in the world most importantly in the growing nations. Rapid growth of towns with none or inadequate infrastructural facilities have been singled out to be responsible for the accumulation of large quantities of wastes. This huge quantity of waste generation coupled with improper disposal methods result in environmental pollution which is a menace to all life forms (Ojeshina \& Lounge, 1996; Ayotamuno \& Gobo, 2004; Kaundal \& Sharma, 2007).

It is evident that most developed nations produce more garbage than developing countries (Kathiravale \& Mohd Yunus, 2008), but Hazra \& Goel (2009) and Bai \& Sutanto (2002) have problems with the enactment of the waste management laws. Weak enforcement, lack of technology and ineffective policy implementation are some of the major enactment problems (Hazra \& Goel, 2009; Bai \& Sutanto, 2002). The disposal of solid waste is influenced by factors such as cost of disposal i.e. cost of labor needed to be taken into consideration, characteristics of the waste to be disposed, availability of disposal site (Ojewale, 2014).

Several scholars observed that to have a functional system to manage solid waste, there's need to investigate socio-economic characteristics. Kayode and Omole (2011) sought to establish the determinants of waste disposal methods and the socio-economic characteristics in Benin City, Nigeria and found that some of the factors influencing waste disposal are age, marital status, occupation, education level, size of household, duration of stay in that area, type of residence. It was established that, waste disposal methods in Lagos include disposal of waste on river banks, dumping waste in drain after rainfall, dumping waste in designated and open spaces, using uncompleted buildings, vacant land, burning and burying, collection by government refuse vans.

From a study done in Lagos, Nigeria it was established that, $16.2 \%, 10.5 \%$ and $27.2 \%$ of the residents in the high, medium and low-density areas, respectively, indicated that they often disposed their solid waste in Lagos State Waste Management's (LAWMA) which works as a refuse facility. Residents in the high density with a middle level of income were more likely to utilize burning as a method of waste disposal. As for adults with age range of 56-65 years and residents with secondary school education were also more likely to utilize burning as a method of waste disposal. Residents associated with high income category, and adults (56-65 years) and residents with tertiary education were .582 and .505 times more likely to utilize LAWMA as method of waste disposal. While residents who have lived for 26-40 years were 1.650 times were also more likely to utilize LAWMA facilities as a method of waste disposal.

Residents associated with high income category, and adults with age range of 31-55 years and residents with secondary school education were .543 and 3.534 times more likely to practice dumping of solid waste on the roadside as a disposal method. Dumping household solid waste in the drains as a disposal method was mainly utilized by residents with high income level and young adults ranging between 31-35 years and those with secondary school education. Residents who have lived for 26-40 years, residents associated with high income category, and the adults (56-65) were most likely to use disposal method of dumping in nearby open space.

All these methods of waste disposal utilized were not environmentally friendly. This study came to a conclusion that disposal methods were dependent on socioeconomic characteristics of residents (density, income, age, educational status, and length of stay) and domestic solid waste disposal methods varied significantly. This study suggests public enlightenment that will be consistent on presenting benefits and dangers of making the environment clean. It should act as an avenue through which residents get to be educated on their roles in achieving a clean healthy environment using healthy solid waste disposal methods.

\subsection{Study Methodology}

The study was carried out in Migori town in Migori County, Kenya. The county has 8 sub-counties, 23 divisions, 88 locations and 202 sub- locations. The town urban population is estimated at 53,100 (2009 Census). The town serves as a market hub for communities residing along the border of Kenya and Tanzania. The high population is attributed to favorable climatic conditions, its proximity to Kenya-Tanzania border for trade and existence of relatively adequate social-amenities such as banks, housing, and health services. The main economic activities include agriculture, fishing, manufacturing and mining. In addition to that communities are engaged in SMEs including but not limited to the Jua Kali sector, woodwork and carpentry, tailoring, welding etc. 


\subsection{Sampling Methods and Data Collection}

The county has five urban towns with population of over 10,000 persons. They include Migori, Kehancha, Awendo, Rongo and Isebania. Purposive simple sampling method was used to select Migori town. The choice of one location was justified being the hub of the economy in Migori and nearing communities, it was easier to collect data as a representative of nearby communities due to the homogenous effect thus information could easily be generalized. Migori town has a population projection of 70,272 (2009,) Census based on the household's distribution and Yamane (1967) sample size determination formula, proportionate sampling method was used to calculate the sample size for each sub-location. With assistance of sub-chiefs, a list of all households was compiled and simple random sampling utilized to identify individual households. Primary data was collected using a structured questionnaire. The sample size that was arrived at was 199 respondents whose responses were analyzed and conclusions drawn as representatives of the entire population.

\subsection{Theoretical and Empirical Framework}

Utilization of awareness and choice of waste disposal methods can be anchored on random utility theory and the characteristic theory of value (Lancaster, 1966; Manski, 1977). The utility an individual i obtain from choosing to utilize a given choice of waste disposal method or not can be specified as;

$U i=V i+\varepsilon i$

Where $U$ is the utility, $V$ is a vector of observable characteristics and $\varepsilon$ captures unobservable character ristics? An individual preference on utilising waste disposal methods if and only if he/she derives utility. This behavior can be modeled using probabilistic models (Greene, 2012).

To determine covariates of awareness and choice of waste disposal methods, probit regression was employed. The choice of waste disposal; use of dustbin, burning, burying and road side as a dummy variable where one (1) denoted choice of waste disposal and zero (0) otherwise. The probit regression was specified as;

$C K i=X i \beta+\varepsilon i$

Where $C K i$ denotes a dummy variable of waste disposal methods awareness, $\mathrm{X}$ is a vector of covariates that include household size, gender, employment status, age, marital status, level of income and residence characteristics, $\beta$ 's are parameters to be estimated, $\varepsilon$ is the stochastic error term and i denotes the respondent.

As a result, an individual's' level of awareness and choice of waste disposal method is influenced by various factors. The choice of waste disposal method could be made simultaneously implying that the error terms of each adaptation equation may be correlated, consequently the multivariate probit model need to be used to account for this correlation.

Given the simultaneity nature of the adaptation decisions, this paper utilized multivariate Probit model that was specified as;

$A S_{i j}^{*}=X_{i}^{\prime} \Pi_{j}+\varepsilon_{i j}$

Where $A S_{i j}^{*}$ denotes the unobserved preferences associated with $\mathrm{j}^{\text {th }}$ choice of waste disposal method for household $\mathrm{i}, \mathrm{X}$ is a vector of covariates that include household size, gender, employment status, age, marital status, level of income and residence characteristics, $\pi$ 's are parameters to be estimated and $\varepsilon$ is the stochastic error term. The choice of waste disposal discussed include: use of dustbin, burning, burying and roadside dumping.

\section{Findings and Discussions}

\subsection{Descriptive Statistics}

According to the responses, it was noted that majority (58.3\%) of the respondents' preference method of waste disposal was the dustbin. This could imply that individuals' awareness and choice of waste disposal method would determine which method to use to dispose of waste and that most residents have knowledge on proper waste disposal and benefits of using the dustbin. The existing urban laws on waste disposal and drainage that urban dwellers need to adhere to contributes to the increase use of dustbin as a way of avoiding penalty that comes with breaking the act. In addition to that, individuals/households like to live in a habitable community free from infectious diseases. The least preferred method was burying (5.67\%). This could be attributed to that being an urban town, there is inadequate space where one could bury their waste. In addition to that, some waste takes years to decompose e.g. plastic others with such as electronic waste which can be hazardous makes them aware of best practice of waste disposal mechanism. 
TABLE 1:DESCRIPTIVE STATISTICS ON CHOICE OF WASTE DISPOSAL METHOD

\begin{tabular}{|l|l|l|l|}
\hline Waste Disposal Methods & Frequency & Percent of Responses & Percent of Cases \\
\hline Dustbin & 195 & 58.38 & 81.25 \\
\hline Roadside & 31 & 9.28 & 12.92 \\
\hline Burying & 19 & 5.69 & 7.92 \\
\hline Burning & 89 & 26.65 & 37.08 \\
\hline Total & 334 & 100.00 & 139.17 \\
\hline
\end{tabular}

Other methods of dumping waste include burning $(26.65 \%)$ and roadside $(9.28 \%)$. The roadside percentage could be explained by factors like, road users such as motorists, pedestrians' children etc. dispose waste along the road despite some pathways having dustbins at designated roadside. The burning method is also least preferred because of reasons such as the environmental pollution that comes with burning waste. Majority of urban dwellers live in apartments and modern residences making it difficult to burn waste.

\subsection{Choice of waste disposal methods.}

The results from the probit regression on awareness and choice of waste disposal methods as illustrated in (table 2) show that the household size, employment status, residency, education, motor vehicle, bicycle were significant determinants of choice of waste disposal methods. This indicates that the probability on the choice of waste disposal methods and individuals utilizes is influenced by awareness which is dependent on various factors. Urban dwellers place of residency will determine which methods of waste disposal will likely be adopted. Individuals' level of education will influence the choice of waste disposal one is likely to use. This means that the more educated an individual is the more likely to be aware on choice of waste disposal methods. Education enables an individual to make rational decision on choice of waste disposal compared to those without decision. This results support that of Rotich et al 2006 who stated that choice of waste disposal method was high with individuals who are educated and practice on their choice compared to less educated and inexperienced respondents. The results further indicate that individuals with motor vehicle awareness of waste disposal method is likelihood to facilitate their decision making on the choice of waste disposal method to use.

The probit regression analysis on the awareness and choice of waste disposal methods confirmed previous studies conducted. Bryan (2013), advances that individuals perceptions and decisions are based on past observation and practices and that these observations modified individuals' behavior over time on waste disposal. Alauddin and Rashid (2014), indicated that household characteristics such as age, gender, and educational characteristics were the key determinants of adoption. Lack of adequate knowledge and information has been reported in previous studies as an obstacle to adaptation (Pandey et al., 2018). According to), knowledge is key and essential input in the process of adaptation. Before adaptation, awareness of waste disposal methods is predominant so as to stimulate the adaptation process (Niles \& Mueller, 2016).

TABLE 2: PROBIT REGRESSION MODEL FOR CHOICE OF WASTE DISPOSAL METHODS

\begin{tabular}{|l|l|l|l|l|}
\hline & $(1)$ & $(2)$ & $(3)$ & $(4)$ \\
\hline Variables & Dustbin & Roadside & Burying & Burning \\
\hline Household Size & -0.0747 & $0.1296^{*}$ & 0.0227 & -0.0080 \\
\hline & $(0.0589)$ & $(0.0727)$ & $(0.0827)$ & $(0.0570)$ \\
\hline Awareness of Waste Disposal & $0.7347^{* * *}$ & -0.2084 & 0.2365 & 0.1750 \\
\hline & $(0.2730)$ & $(0.2980)$ & $(0.4370)$ & $(0.2915)$ \\
\hline Improvement & 0.5142 & 0.3711 & $-1.4669^{* * *}$ & 0.3155 \\
\hline & $(0.3268)$ & $(0.4145)$ & $(0.4116)$ & $(0.3306)$ \\
\hline Gender & -0.1484 & -0.0972 & 0.1139 & 0.0264 \\
\hline & $(0.2493)$ & $(0.2574)$ & $(0.3461)$ & $(0.2157)$ \\
\hline
\end{tabular}


Civil and Environmental Research

\begin{tabular}{|c|c|c|c|c|}
\hline Employment Status & 0.4640 & -0.2456 & $-0.8789 *$ & $-0.8915 * * *$ \\
\hline & $(0.3443)$ & $(0.3837)$ & $(0.4918)$ & $(0.3160)$ \\
\hline \multirow[t]{2}{*}{ residence_D2 } & 0.1347 & 0.0676 & 0.2197 & 0.2599 \\
\hline & $(0.2512)$ & $(0.2716)$ & $(0.3460)$ & $(0.2134)$ \\
\hline \multirow[t]{2}{*}{ residence_D3 } & -0.0710 & $0.8222 * *$ & -0.2700 & $1.4937 * * *$ \\
\hline & $(0.3562)$ & $(0.3904)$ & $(0.4735)$ & $(0.3510)$ \\
\hline \multirow[t]{2}{*}{ age_D2 } & -0.2420 & 0.2956 & -0.6746 & 0.2155 \\
\hline & $(0.3340)$ & $(0.3655)$ & $(0.4272)$ & $(0.3056)$ \\
\hline \multirow[t]{2}{*}{ age_D1 } & -0.3372 & 0.0821 & -0.3958 & 0.2884 \\
\hline & $(0.6568)$ & $(0.7534)$ & $(0.8285)$ & $(0.7481)$ \\
\hline \multirow[t]{2}{*}{ marital_status_D2 } & 0.1759 & -0.0455 & 0.5606 & -0.1738 \\
\hline & $(0.2616)$ & $(0.3017)$ & $(0.3508)$ & $(0.2385)$ \\
\hline \multirow[t]{2}{*}{ marital_status_D5 } & -0.2577 & - & 1.1517 & 0.1486 \\
\hline & $(0.6878)$ & & $(0.8888)$ & $(0.6225)$ \\
\hline \multirow[t]{2}{*}{ education_D2 } & -0.1312 & $-0.5484 *$ & $1.4255 * * *$ & $-0.4127 *$ \\
\hline & $(0.2757)$ & $(0.2868)$ & $(0.4044)$ & $(0.2377)$ \\
\hline \multirow[t]{2}{*}{ education_D3 } & -0.3035 & -0.1252 & 0.4684 & -0.2886 \\
\hline & $(0.3275)$ & $(0.3477)$ & $(0.4354)$ & $(0.2898)$ \\
\hline \multirow[t]{2}{*}{ income_D4 } & $0.4153 *$ & -0.1982 & -0.0562 & -0.1521 \\
\hline & $(0.2360)$ & $(0.2504)$ & $(0.2733)$ & $(0.2150)$ \\
\hline \multirow[t]{2}{*}{ Motor Vehicle } & -0.0261 & 0.1857 & $0.8563 * *$ & 0.1499 \\
\hline & $(0.3423)$ & $(0.3874)$ & $(0.4251)$ & $(0.3087)$ \\
\hline \multirow[t]{2}{*}{ Motorcycle } & $0.5705^{*}$ & -0.0999 & $-1.0383^{* *}$ & 0.0858 \\
\hline & $(0.3010)$ & $(0.2960)$ & $(0.4569)$ & $(0.2362)$ \\
\hline \multirow[t]{2}{*}{ Bicycle } & 0.1419 & $-1.2430 * * *$ & $0.7420^{*}$ & -0.0254 \\
\hline & $(0.3525)$ & $(0.4648)$ & $(0.4466)$ & $(0.2888)$ \\
\hline \multirow[t]{2}{*}{ Constant } & 0.0958 & $-1.5236^{*}$ & $-1.2879 *$ & -0.5971 \\
\hline & $(0.6552)$ & $(0.7785)$ & $(0.7071)$ & $(0.6011)$ \\
\hline Wald Chi Square & $32.17 * *$ & $18.40 *$ & $46.90 * * *$ & $35.19^{*}$ \\
\hline Pseudo R Squared & 0.1232 & 0.0950 & 0.2634 & 0.1392 \\
\hline Observations & 235 & 230 & 235 & 235 \\
\hline
\end{tabular}

Robust standard errors in parentheses

$* * * \mathbf{p}<0.01, * * \mathbf{p}<0.05, * \mathbf{p}<0.1$ 


\section{Conclusion}

Waste management is currently a serious problem with evidences of increased poor disposal methods resulting to adverse effects on the environment and spread of diseases. Despite this, there is still knowledge deficit among members of the public on proper waste disposal thus negatively affecting the measures to improve on waste management. Rapid population growth in Migori County has consequently resulted in an increase in the generation of waste but due to lack of public awareness or concern regarding proper waste disposal and waste issues among the people, disposal of the waste has remained a major issue still to be addressed despite the governments and partly the society's efforts to curb the problem. The existing systems, though partly effective, suffer from lack of support and cooperation from the private sector. Since public awareness and attitude has an impact on all stages of the waste management process, the government as well as NGOs should make efforts to increase public awareness on waste disposal methods and participation regarding waste management challenges in developing countries-Kenyan case study. Waste management methods through the media.

The research paper sought to give insights on residents' knowledge on waste disposal methods and factors that influence the choice of the method to use while disposing off waste with a view of informing policy on the appropriate and proper method to waste disposal and dissemination. The research paper on awareness and choice of waste disposal methods by residents of Migori town, concludes that more information on proper waste disposal methods should be aired on radio and TV since majority of the respondents indicated radio and TV as the main source of waste management information. Further, the research concludes that household size, employment status, area of residency and level of education were also key determinants to choice of waste disposal methods and thus more effort should be put on education since employment status and area of residency were determined by time, which we have limited control over.

In conclusion therefore, the researchers recommend for further research on the choice and level of awareness of waste disposal methods. The study also recommends that similar research should be conducted in different counties since the sample size was small and may not provide conclusive results.

\section{REFERENCES}

Lancaster, (1966). A new approach to consumer theory. Journal of political economy, 74(2), 132-157. Abid et al. (2016). Adaptation to climate change and its impacts on food productivity and crop income: Perspectives of farmers in rural Pakistan. Journal of rural studies, 47(A), 254-266.

Alauddin, M., \& Rashid, A. (2014). Climate change and farm-level adaptation decisions and strategies in droughtprone and groundwater-depleted areas of Bangladesh. An empirical investigation: Journal of ecological economics, 106, 204-2013.

Ayotamuno, J., \& Gobo, A. (2004). Municipal solid waste management in Port Harcourt, Nigeria. Management of environmental quality: An International Journal, 15(4), 389-398.

Bai, E., \& Sutanto, M. (2002). The practice and challenges of solid waste management in Singapore. Waste management, 22(5), 557-567.

Bello et al. (2016). Solid waste management in Africa. International Journal of Waste Resources. 6(2), 4-7.

Bryan, E. et al. (2013). Journal of Environmental Management (115), 1-300.

Greene, (2012). A review of national municipal solid waste generation assessments in the USA. Waste Management \& Research, 30(8), 758-771.

Hazra \& Goel, (2009). Solid waste management in Kolkata, India. Waste management, 29(1), 470-478. Henry, E. et al. (2006). Municipal solid waste management challenges in developing countries-Kenyan case study. Waste management, 26(1), 92-100.

Kathiravale, \& Mohd, Y. (2008). Waste management in the city of Shah Alam, Malaysia. Transactions on Ecology and the Environment, 109, 605-611.

Kaundal \& Sharma (2007). Problems of household waste disposal. Journal of Human Ecology, 21(3), 199-201

Kayode, A., M., \& Omole, F. K. (2011). Some socio-economic factors affecting solid wastes Generation and disposal in Ibadan metropolis, Nigeria. Journal of Environmental Issues and Agriculture in Developing Countries, 3(1), 55-64.

Manski, (1977). The structure of random utility models. Theory and decision, 8(3), 229-254.

Metropolitan transfer station (2017). Analysis of waste generation variables and people's attitudes towards waste management system: a case of Bangkok, Thailand. Journal of Material Cycles and Waste Management, 19(2), 645-656.

Mutanu, (2018). A self-learning approach for validation of runtime adaptation in service-oriented systems. Service Oriented Computing and Applications, 1-14.

Niles \& Mueller, (2016). Farmer perceptions of climate change: Associations with observed temperature and precipitation trends, irrigation, and climate beliefs. Global environmental change, 39, 133-142.

Ojewale (2014). Intraurban analysis of domestic solid waste disposal methods in a sub-sahara African city. Journal of Waste Management. 
Oyake (2018). Ultimate confinement of phonon propagation in silicon nanocrystalline structure. Physical review letters, 120(4), 045901.

Pandey et al. (2018). One-year operation of 1000-L modularized microbial fuel cell for municipal wastewater treatment. Water research, 141, 1-8.

World Bank. (2018). What a waste: A global review of solid waste management, 15, 116. Yamane., (1967). Sensitized photodimerization of thymine in DNA. Proceedings of the National Academy of Sciences of the United States of America, 58(2), 443.

Tadesse, T., Ruijs, A., \& Hagos, F. (2008). Household waste disposal in Mekelle city, Northern Ethiopia. Waste Management, 28(10), 2003-2012.

Parrot, L., Sotamenou, J., \& Dia, B. K. (2009). Municipal solid waste management in Africa: Strategies and livelihoods in Yaoundé, Cameroon. Waste Management, 29(2), 986-995.

Rotich, K.H., Yonsheng, Z., Jun, D., 2006. Municipal solid waste management challenges in developing countries - Kenyan study. Waste management, 26, 92-100.

Larsen, L., Yeshitela, K., Mulatu, T., Seifu, S., \& Desta, H. (2019). The Impact of Rapid Urbanization and Public Housing Development on Urban Form and Density in Addis Ababa, Ethiopia. Güneralp, B., Lwasa, S., Masundire, H., Parnel, S., \& Seto, K. (2017) Urbanization in Africa: challenges and opportunities for conservation. Environmental Research Letters, 13(1).

Okumu. J. (October 26th 2012). Solid Waste Management in African Cities - East Africa, Waste Management.

Sibanda, L.K., Obange, N. \& Awuor, F.O. Urban Forum (2017). Challenges of Solid Waste Management in Kisumu, Kenya 28(387).

Hope, K. (1998). Urbanization and Urban Growth in Africa. Journal of Asian and African Studies. 33, 345-358. 